\title{
Underbody blankets have a higher heating effect than overbody blankets in lithotomy position endoscopic surgery under general anesthesia: a randomized trial
}

\author{
Kentaro Hara ${ }^{1,2}$ D $\cdot$ Hiromi Kuroda $^{2} \cdot$ Emi Matsuura $^{2} \cdot$ Yuji Ishimatsu $^{2} \cdot$ Sumihisa Honda $^{2} \cdot$ Hiroaki Takeshita $^{3}$. \\ Terumitsu Sawai ${ }^{2}$
}

Received: 19 September 2020 / Accepted: 13 January 2021 / Published online: 29 January 2021

(c) The Author(s), under exclusive licence to Springer Science+Business Media, LLC part of Springer Nature 2021

\begin{abstract}
Background Surgery under general anesthesia results in temperature decrease due to the effect of anesthetics and peripheral vasodilation on thermoregulatory centers. Perioperative temperature control is therefore an issue of high importance. In this study, we aimed to compare the warming effect of underbody and overbody blankets in patients undergoing surgery in the lithotomy position under general anesthesia.

Methods From September 2018 to October 2019, 99 patients undergoing surgery for colorectal cancer in the lithotomy position were included in this randomized controlled trial and assigned to the intervention group (underbody blanket) or control group (overbody blanket).

Results The central temperature was significantly higher in the underbody blanket group than in the overbody blanket group at 90 min after the beginning of the surgery $(p=0.02)$; also in this group, the peripheral temperature was significantly higher 60 min after the beginning of the surgery $(p=0.02)$. Regarding postoperative factors, the underbody blanket group had a significantly lower frequency of postoperative shivering $(p<0.01)$ and a significantly shorter postoperative hospital stay $(p=0.04)$ than the overbody blanket group.

Conclusions We recommend the use of underbody blankets for intraoperative temperature control in patients undergoing surgery in the lithotomy position under general anesthesia. Underbody blankets showed improved rise and maintenance of central and peripheral temperature, decreased the incidence of postoperative shivering, and shortened the postoperative length of hospital stay.
\end{abstract}

Keywords Underbody blanket · Overbody blanket · Lithotomy position · General anesthesia

Surgery under general anesthesia causes suppression of the thermoregulatory center and peripheral vasodilation, leading to a decrease in central temperature of $1-3{ }^{\circ} \mathrm{C}[1-3]$. It has been reported that intraoperative hypothermia increases surgical site infection (SSI), prolongs the hospital stay,

Kentaro Hara

hara.kentaro.yu@mail.hosp.go.jp

1 Department of Operation Center, National Hospital Organization Nagasaki Medical Center, Kubara 2-1001-1, Omura, Nagasaki 856-8562, Japan

2 Nagasaki University Graduate School of Biomedical Sciences, Nagasaki 852-8523, Japan

3 Department of Surgery, National Hospital Organization Nagasaki Medical Center, Nagasaki 856-8562, Japan increases the cost of medical care, and increases bleeding risk. The need for maintaining normothermia in the perioperative period has been shown to play a role in postoperative recovery [4-6]. In addition, studies on intraoperative warming and prevention of perioperative complications have reported that hypothermia leads to delayed arousal due to decreased hepatic drug-metabolizing enzyme activity [7-9].

There are four types of heat transfer in the human body: radiation, convection, evaporation, and conduction [10]. Because $90 \%$ of the heat is delivered through the skin, this surface is required to safely transfer large amounts of heat to the patient [11]. Specific intraoperative patient warming methods have been used in the past to provide heat through radiation and conduction, and through hot water circulation systems. In recent years, the effectiveness of hot air heaters, which envelop the patient with hot air and transfer 
heat by convection, contrary to hot water circulation heaters, which only heat the area in contact with the patient, has been reported $[12,13]$.

There are two types of hot air heaters: the overbody blanket, which warms the patient from above, and the underbody blanket, which warms the patient from below. However, with the recent development of laparoscopic surgery, the number of surgeries performed in the lithotomy position has rapidly increased, while the number of cases of intraoperative hypothermia has dramatically increased. Therefore, it is necessary to improve the temperature control methods and the body heating area because lithotomy often involves upper extremity restraining. However, the area of warmth is frequently limited to the neck and part of the anterior thorax. If an underbody blanket is used, the patient is heated from the head to the buttocks, which is likely to be more effective in preventing intraoperative hypothermia. Nevertheless, due to the higher cost of the underbody heating system, it is difficult to implement its widespread use without supporting evidence. Although there have already been previous studies showing the effectiveness of underbody heating systems for supine surgery [14-16], there are no reports on their effectiveness for procedures performed in the lithotomy position.

We considered that it is necessary to carry out basic research to clarify the effect of the underbody blanket in surgeries performed with the patient in the lithotomy position.

\section{Materials and methods}

\section{Study setting and population}

The study was a single-blind randomized controlled trial conducted between September 2018 and November 2019 in the operating rooms of the National Hospital Organization in Nagasaki, Japan. All participants were at least 20 years old at the time of obtaining consent to perform colon cancer laparoscopic surgery under general anesthesia. Patients were fully informed regarding their participation in the study and confirmed their full understanding before providing written consent, which was obtained after confirming that participation in the study was secure. Exclusion criteria were emergency surgery for colorectal cancer, a family history of malignant high fever, and drug sensitivity (i.e., patients with allergies). The research process was fully explained to the participants and their families. The required number of patients was calculated using $G$ * power 3.1.9.4 (HeinrichHeine Universität, Dusseldorf, Germany) considering an effect size, power, and $\alpha$ of $0.6,0.9$, and 0.05 , respectively. Ninety patients (45 patients in each group) were deemed necessary. A total of 100 patients (50 patients in each group) were enrolled considering a dropout rate of $10 \%$.

\section{Ethical considerations}

This study was approved by the Ethics Committee of the Nagasaki University Graduate School of Medicine, Dentistry and Pharmaceutical Sciences (No. 18071204) and by the Ethics Committee of the Nagasaki Medical Center (No. 30071), where the research was conducted. This study was registered with the University Hospital Medical Information Network Center (ID: 000,034,019). The CONSORT checklist was used to report the study [17].

\section{Design and randomization}

We stratified patients into those under and over 70 years old, respectively, taking into account the median age of patients who underwent elective colorectal cancer surgery under general anesthesia between 2016 and 2018. Equal randomization to the intervention (the underbody blanket) and control (the overbody blanket) groups was achieved via a computergenerated random sequence list. Concealed allocation was ensured as the research assistant conducting randomization received the group assignment without access to participant information.

\section{Outcomes}

The primary endpoint was intraoperative central temperature. Secondary endpoints were intraoperative peripheral temperature, intraoperative blood loss, postoperative shivering, postoperative complications, and postoperative hospital length of stay.

As central temperature, we measured the tympanic temperature when patients entered and exited the operating room, and measured the esophageal temperature from the time of induction of anesthesia until the end of surgery: during anesthesia initiation; at the initiation of surgery; 30, 60, 90,120 , and $180 \mathrm{~min}$ later; and after surgery completion. The measurement of tympanic temperature shows errors depending on the angle; thus, the average of three tympanic membrane temperature measurements was used to correct for errors due to the angle at the time of measurement.

We measured the skin temperature on the dorsum of the hands at the same timepoints used for the central temperature.

\section{Warming methods}

A $3 \mathrm{M}^{\mathrm{TM}}$ Bear Hugger ${ }^{\mathrm{TM}}$ Patient Warming Model 675 (Arizant Healthcare Inc., Prairie, MN) was used as an air heater. The operating table was warmed using the $3 \mathrm{M}^{\mathrm{TM}}$ Bear Hugger $^{\mathrm{TM}}$ Postoperative Blanket Model 300 (Arizant Healthcare 
Inc., Prairie, MN). The temperature was increased to $43{ }^{\circ} \mathrm{C}$ $30 \mathrm{~min}$ before the patient was scheduled to enter the operating room.

Preoperative warming from entry into the operating room to the initiation of surgery was performed using the $3 \mathrm{M}^{\text {тм }}$ Bear Hugger ${ }^{\mathrm{TM}}$ postoperative Blanket Model 300 (Arizant Healthcare Inc., Prairie, MN). The subjects were warmed at $43{ }^{\circ} \mathrm{C}$ in the supine position from the time they were lying on the operating table until just before the initiation of surgical positioning.

The heating fluid used was Physio® 140 (Otsuka Pharmaceutical Co., Ltd, Japan), which was warmed in an operating room warming cabinet (set at $37^{\circ} \mathrm{C}$ ).

\section{Intervention group (underbody blanket group)}

A $3 \mathrm{M}^{\mathrm{TM}}$ Bear Hugger ${ }^{\mathrm{TM}}$ Underbody Blanket 585 (Arizant Healthcare Inc., Prairie, MN) was used in the intervention group. To enhance the heating effect, the attached head drape was used on the head and neck of the study participants. To heat the thighs, the strips on either side of the lower body blanket were tied to the thighs of the participants. The hot air heater was activated after the surgical position was fixed and before the start of the surgery so that the hot air was not cut off during surgery.

\section{Control group (overbody blanket group)}

A $3 \mathrm{M}^{\mathrm{TM}}$ Bear HuggerTM Patient Warming Blanket 622 (Arizant Healthcare Inc., Prairie, MN) was used. The head drapes attached to the head and neck of the participants were used to increase heat retention. Both upper and lower extremities were covered with towelettes for insulation.

\section{Warming area}

The warming area of the under- and overbody blankets were calculated using the formula of Lund and Browder [18]. This formula, which is used to calculate the area of burns, was adopted because it is possible to calculate the area of each body part in detail, and it was deemed applicable to the measurement of the heated area in this study.

\section{Anesthesia procedure}

After entering the operating room, the electrocardiogram leads, blood pressure cuff, and pulse oximeter were fixed with the patient in the supine position. The anesthesiologist in charge administered $0.6-1.0 \mathrm{mg} / \mathrm{kg}$ of propofol, $0.3 \mu \mathrm{g} / \mathrm{kg} / \mathrm{min}$ of remifentanil, and $0.6 \mathrm{mg} / \mathrm{kg}$ of rocuronium to induce anesthesia. When sufficient muscle relaxation was obtained, the tracheal tube was intubated into the main bronchus by direct or video laryngoscopy.
Anesthesia was maintained using sevoflurane, desflurane, remifentanil, or rocuronium in most cases at the discretion of the anesthesiologist in charge. Total intravenous anesthesia with propofol was performed in a few cases. Intraoperative ventilator settings were set at a tidal volume of $6-8 \mathrm{ml} / \mathrm{kg}$, positive end expiratory pressure of $4-8 \mathrm{~cm}$ $\mathrm{H}_{2} \mathrm{O}$, respiratory rate of 10-14 cycles/min, and fraction of inspired oxygen of 0.4 . An open arterial pressure line was placed in the radial artery of the study subjects. The anesthesiologist administered ephedrine, phenylephrine, dopamine, and hydroxyethyl starch $6 \%$ so that the mean blood pressure was greater than $60 \mathrm{mmHg}$.

Fifteen $\mathrm{mg} / \mathrm{kg}$ of acetaminophen and $50 \mathrm{mg}$ of nonsteroidal anti-inflammatory drugs were administered for analgesia purposes before the end of surgery. Using a pharmacokinetic simulation, fentanyl was administered so that the effective site concentration at the time of awakening was $1-2 \mathrm{ng} / \mathrm{ml}$. Four mg/kg sugammadex were administered before extubation, which was performed after the stabilization of spontaneous ventilation and the recovery from muscle relaxation. After extubation, the patient was transferred to the postoperative observation room or the intensive care unit.

\section{Data collection and statistical analyses}

The primary and secondary endpoints, patient background data, intra- and postoperative factors, and pre-post surgery differences in median central and peripheral were compared between groups. Two-sided $p$-values were used, and values under 0.05 were considered to indicate statistical significance. All statistical analyses were performed using JMP® 14 (SAS Institute Inc., Cary, NC). A $t$-test or one-way analysis of variance was used for between-group comparisons of continuous variables if data were normally distributed or Mann-Whitney $U$ test if normality was not found. Chi-squared and Fisher's exact tests were used for discrete variables.

\section{Results}

\section{Overview of participants}

Among the 106 patients scheduled for surgery during the study period, 100 patients provided consent and were enrolled and randomly allocated into the study groups. Of these, 99 were included in the analysis because one patient withdrew consent after participating in the study. There were no cases lost to follow-up (Fig. 1). Patient background data are shown in Table 1. There was no significant difference in patient background characteristics between groups. 
Fig. 1 Trial CONSORT diagram. Among the 106 patients scheduled for surgery during the study period, 100 patients provided consent and were enrolled and randomly allocated into the study groups. Of these, 99 were included in the analysis because one patient withdrew consent after participating in the study

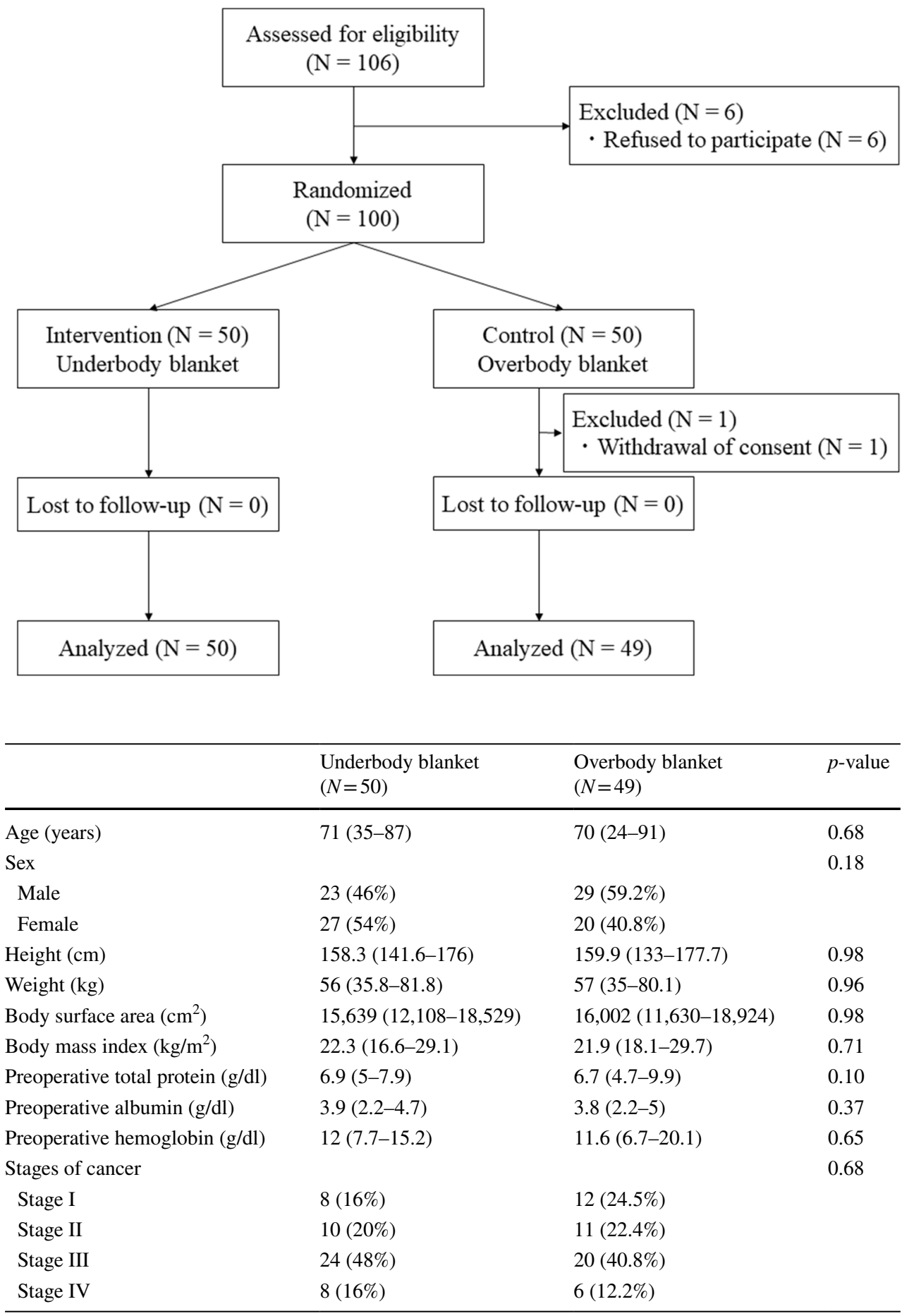

Values are presented as medians (ranges) or number of patients (\%). Mann-Whitney- $U$ test was used for comparisons of ordinal data. Nominal data were compared using the Chi-squared test

\section{Comparison of intraoperative factors}

Intraoperative factors for the intervention and control groups are shown in Table 2. There was no significant difference in intraoperative factors between groups.

\section{Comparison of changes in central temperature}

Changes in the central temperature are summarized in Table 3 and Fig. 2. Ninety minutes postoperatively, central 
Table 2 Intraoperative factors

\begin{tabular}{|c|c|c|c|}
\hline & $\begin{array}{l}\text { Underbody blanket } \\
(N=50)\end{array}$ & $\begin{array}{l}\text { Overbody blanket } \\
(N=49)\end{array}$ & $p$-value \\
\hline Preoperative room temperature $\left({ }^{\circ} \mathrm{C}\right)$ & $26(25-27)$ & $26(25-27)$ & 0.54 \\
\hline Intraoperative room temperature $\left({ }^{\circ} \mathrm{C}\right)$ & $23.5(22.5-24.5)$ & $23.5(22-24.5)$ & 0.22 \\
\hline Postoperative room temperature $\left({ }^{\circ} \mathrm{C}\right)$ & $26(24.5-27)$ & $26(24.5-27)$ & 0.84 \\
\hline Operative time $(\min )$ & $324(178-900)$ & $330(182-671)$ & 0.98 \\
\hline Anesthetic time (min) & $414.5(252-977)$ & $453(225-816)$ & 0.81 \\
\hline Type of anesthesia & & & 0.57 \\
\hline Sevoflurane & $29(58 \%)$ & $32(65.3 \%)$ & \\
\hline Desflurane & $19(38 \%)$ & $14(28.6 \%)$ & \\
\hline Propofol & $2(4 \%)$ & $3(6.1 \%)$ & \\
\hline Amount of bleeding $(\mathrm{ml})$ & $30(2-795)$ & $30(3-635)$ & 0.75 \\
\hline Urine volume (ml) & $332.5(70-2250)$ & $30(3-635)$ & 0.64 \\
\hline Total fluid volume (ml) & $2233(1240-4819)$ & $2553(1039-5719)$ & 0.15 \\
\hline Warming area $\left(\mathrm{cm}^{2}\right)$ & $5708(4419-6763)$ & $2400(1744-2839)$ & $<0.01^{*}$ \\
\hline Infusion warming apparatus & & & 0.11 \\
\hline Used & $0(0 \%)$ & $3(6.1 \%)$ & \\
\hline Not used & $50(100 \%)$ & $46(93.9 \%)$ & \\
\hline Intraoperative blood transfusion & & & 0.61 \\
\hline Required & $1(2 \%)$ & $2(4.1 \%)$ & \\
\hline Not required & $49(98 \%)$ & $47(95.9 \%)$ & \\
\hline Intraoperative warming blanket stopped & & & 0.61 \\
\hline Stopped & $18(36 \%)$ & $10(20.4 \%)$ & \\
\hline Not stopped & $32(64 \%)$ & $39(79.6 \%)$ & \\
\hline
\end{tabular}

Values are presented as medians (ranges) or number of patients (\%). Mann-Whitney- $U$ test was used for comparisons of ordinal data. Nominal data were compared using the Chi-squared test or Fisher's exact test

*Significant difference between groups

Table 3 Between-group differences in intraoperative central temperature over time

\begin{tabular}{lllr}
\hline & $\begin{array}{l}\text { Underbody blanket } \\
(N=50)\end{array}$ & $\begin{array}{l}\text { Overbody blanket } \\
(N=49)\end{array}$ & $p$-value \\
\hline When entering the operation room $\left({ }^{\circ} \mathrm{C}\right)$ & $36.3(35.1-37.5)$ & $36.4(34.9-37.7)$ & 0.51 \\
Anesthesia initiation $\left({ }^{\circ} \mathrm{C}\right)$ & $36.5(35.1-37.3)$ & $36.4(35.3-37.6)$ & 0.52 \\
Initiation of surgery $\left({ }^{\circ} \mathrm{C}\right)$ & $36.5(35.6-37.2)$ & $36.4(35.5-37.6)$ & 0.48 \\
30 min later $\left({ }^{\circ} \mathrm{C}\right)$ & $36.7(35.5-37.2)$ & $36.6(35.4-37.5)$ & 0.41 \\
60 min later $\left({ }^{\circ} \mathrm{C}\right)$ & $36.9(35.6-37.2)$ & $36.6(35.7-37.5)$ & 0.09 \\
90 min later $\left({ }^{\circ} \mathrm{C}\right)$ & $37.0(35.8-37.7)$ & $36.7(35.8-37.7)$ & $0.02^{*}$ \\
120 min later $\left({ }^{\circ} \mathrm{C}\right)$ & $37.1(35.6-37.8)$ & $36.8(35.7-37.9)$ & $0.01^{*}$ \\
180 min later $\left({ }^{\circ} \mathrm{C}\right)$ & $37.2(36.1-37.9)$ & $36.8(35.7-37.9)$ & $0.03^{*}$ \\
Completion of surgery $\left({ }^{\circ} \mathrm{C}\right)$ & $37.5(36.4-38.6)$ & $37.1(35.2-38.2)$ & $<0.01^{*}$ \\
When leaving the operating room $\left({ }^{\circ} \mathrm{C}\right)$ & $37.0(35.8-38.5)$ & $36.7(35.3-38.3)$ & 0.05 \\
\hline
\end{tabular}

Values are presented as medians (ranges) or number of patients (\%). Mann-Whitney- $U$ test was used for comparisons of ordinal data

*Significant difference between groups temperature was significantly higher in the intervention group. In the control group, a temperature lower than $36{ }^{\circ} \mathrm{C}$ was observed in two subjects.

\section{Comparison of changes in peripheral temperature}

Changes in peripheral temperature are summarized in Table 4 and Fig. 3. Sixty minutes postoperatively, peripheral 


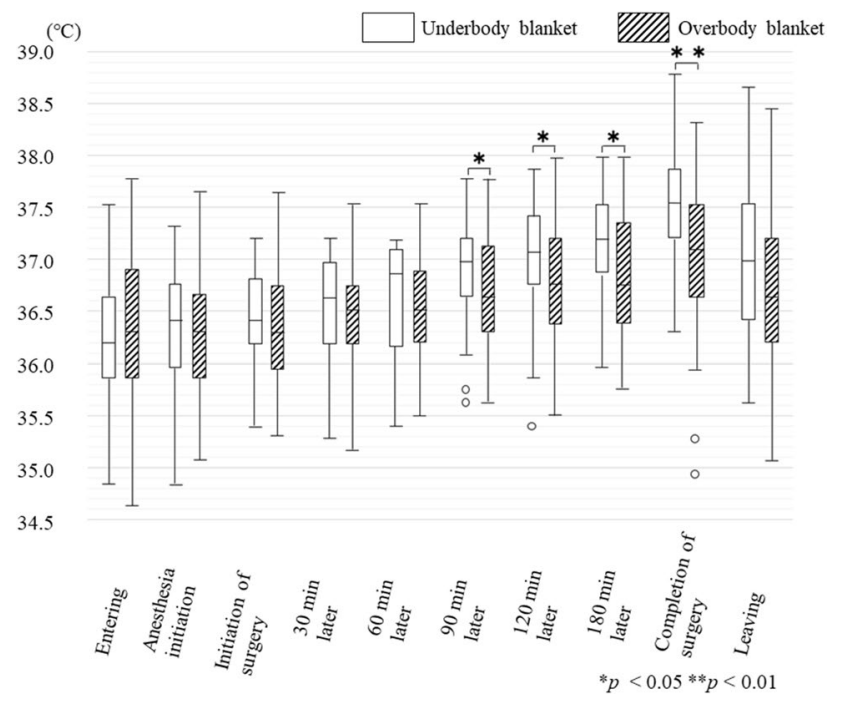

Fig. 2 Ninety minutes postoperatively, central temperature was significantly higher in the intervention group

temperature was significantly higher in the intervention group.

\section{Comparison of differences between central and peripheral temperatures}

The median temperature difference (median central-median peripheral temperature) was $0.7-1.5^{\circ} \mathrm{C}$ in the intervention group and $1.2-2.1{ }^{\circ} \mathrm{C}$ in the control group. The difference between the central and peripheral temperatures was significantly smaller in the intervention group $(p<0.01)$.

\section{Comparison of postoperative factors}

Postoperative factors for the intervention and control groups are shown in Table 5. There were no postoperative complications other than SSI in both groups. The intervention group had a significantly lower frequency of postoperative shivering $(p<0.01)[19]$ and a significantly shorter postoperative length of hospital stay ( $p=0.04)$ than the control group.

\section{Discussion}

Unplanned periodic hypothermia (UPH) has been reported in multiple studies of anesthetized patients, and the importance of normothermia is stated in clinical guidelines [20-23]. The normal central temperature is $36.8-37.0^{\circ} \mathrm{C}$; $\mathrm{UPH}$ is defined as a central temperature below $36.0^{\circ} \mathrm{C}$ [24]. It has been reported that the occurrence of UPH leads to the reduction of hemostatic function, the occurrence of ischemic heart disease, increased risk of pressure ulcers, and patient discomfort [25-29]. It is important to prevent UPH using intraoperative heating. In this study, the use of an underbody blanket was found to prevent UPH compared with an upper body blanket because UPH was observed in only two cases in the control group.

We hypothesized that the underbody blanket would provide a wider and more effective heating area than the overbody blanket for surgeries performed in the lithotripsy position. The median value of each body surface area showed that about 3.3 times more warm air was provided by the underbody blanket. Differences in the heated area were also reported in previous studies [30]. When the prevention of hypothermia is considered, it has been reported that the clinically effective temperature difference is $0.2^{\circ} \mathrm{C}$ or more [31]. In this study, there was a difference of $0.4{ }^{\circ} \mathrm{C}$
Table 4 Between-group differences in intraoperative peripheral temperature over time

\begin{tabular}{lllr}
\hline & $\begin{array}{l}\text { Underbody blanket } \\
(N=50)\end{array}$ & $\begin{array}{l}\text { Overbody blanket } \\
(N=49)\end{array}$ & $p$-value \\
\hline When entering the operation room $\left({ }^{\circ} \mathrm{C}\right)$ & $32.0(27.4-36.6)$ & $32.3(26.9-37.0)$ & 0.18 \\
Anesthesia initiation $\left({ }^{\circ} \mathrm{C}\right)$ & $33.0(27.5-36.2)$ & $33.0(28.4-36.8)$ & 0.59 \\
Initiation of surgery $\left({ }^{\circ} \mathrm{C}\right)$ & $35.0(31.1-38.4)$ & $35.0(30.6-36.6)$ & 0.96 \\
30 min later $\left({ }^{\circ} \mathrm{C}\right)$ & $35.7(31.5-38.0)$ & $35.0(32.0-36.9)$ & 0.39 \\
60 min later $\left({ }^{\circ} \mathrm{C}\right)$ & $36.0(32.2-38.4)$ & $35.3(32.5-36.9)$ & $0.02^{*}$ \\
90 min later $\left({ }^{\circ} \mathrm{C}\right)$ & $36.2(32.0-38.5)$ & $35.5(32.0-36.9)$ & $<0.01^{*}$ \\
120 min later $\left({ }^{\circ} \mathrm{C}\right)$ & $36.2(32.0-38.6)$ & $35.5(32.0-37.1)$ & $<0.01^{*}$ \\
180 min later $\left({ }^{\circ} \mathrm{C}\right)$ & $36.4(31.1-38.3)$ & $35.2(32.4-37.3)$ & $<0.01^{*}$ \\
Completion of surgery $\left({ }^{\circ} \mathrm{C}\right)$ & $36.1(29.8-38.8)$ & $35.0(29.4-37.3)$ & $0.03^{*}$ \\
When leaving the operating room $\left({ }^{\circ} \mathrm{C}\right)$ & $35.7(29.4-37.7)$ & $35.0(26.6-36.9)$ & 0.22 \\
\hline
\end{tabular}

Values are presented as medians (ranges) or number of patients (\%). Mann-Whitney- $U$ test was used for comparisons of ordinal data

*Significant difference between groups 


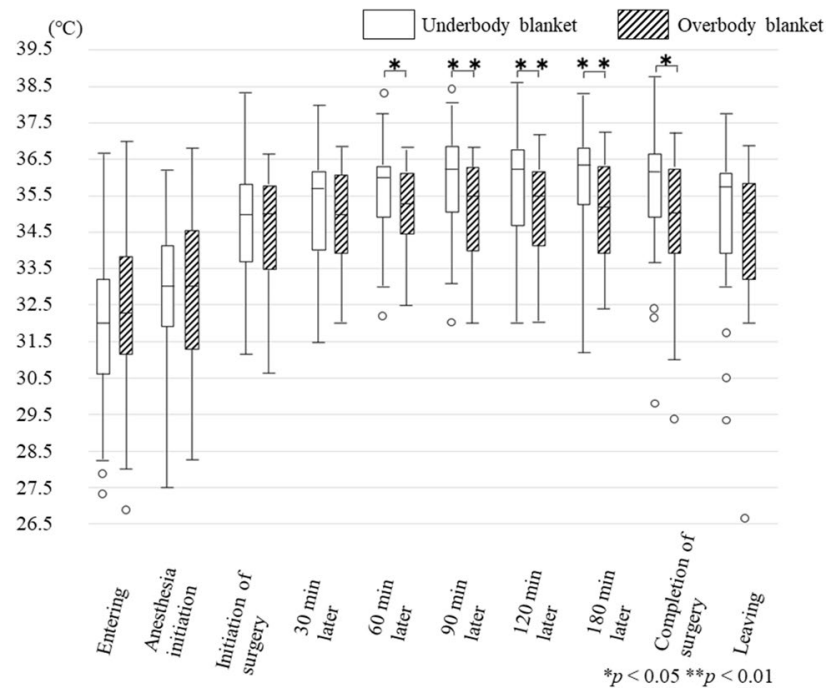

Fig. 3 Sixty minutes postoperatively, peripheral temperature was significantly higher in the intervention group

between the intervention and control groups in the median central temperature at the end of surgery. We assume that the increased heated area of the underbody blanket played a role in the changes in central temperature recorded in the intervention and control groups during surgery.

Postoperative shivering increases the risk of ischemic heart disease, delayed wound healing, and postoperative pain by increasing oxygen consumption from 300 to $400 \%$ and increasing the cardiac burden [32-35]. Shivering after surgery under general anesthesia is frequently preceded by vasoconstriction of apical and toe arteriovenous shunts, an autonomic thermoregulatory response different to symptoms observed during central hypothermia [36]. Vasoconstriction functions to maintain normal central nervous system temperature by decreasing skin and muscle blood flow and reducing heat loss, with significant effects on body heat distribution $[37,38]$. The difference between central and peripheral temperature was significantly different between shivering and non-shivering patients. It was reported that shivering occurs in patients whose peripheral temperature decreased during surgery [39]. In this study, the difference between central and peripheral temperature was significantly lower in the intervention group; this is considered to be one of the factors that limits the generation of postoperative shivering. In addition, it has been reported that increased peripheral temperature linearly decreases the central temperature at which arteriovenous shunt vasoconstriction and shivering occur [40]. According to our findings, the peripheral temperature of the intervention group was significantly higher than that of the control group after $60 \mathrm{~min}$ of surgery. The use of the underbody blanket enables warm air heating to the end of the upper extremity, which has been proven to increase peripheral temperature. It is therefore assumed that the underbody blanket decreased the incidence of postoperative shivering by maintaining the peripheral temperature and preventing a decrease in central temperature, thereby reducing the difference between them.

The postoperative length of hospital stay was significantly shorter in the intervention group. We hypothesized that preventing intraoperative hypothermia would lead to the prevention of SSI and affect the postoperative hospital length of stay. However, there was no significant difference in SSI between groups. There were also no significant differences in disease staging, nutritional status, or blood loss, which may be related to the postoperative hospital length of stay. Significant differences between groups were only observed in intraoperative central and peripheral temperature, postoperative shivering, and length of stay. More specifically, postoperative shivering is related to increased oxygen consumption immediately after surgery, which lowers

Table 5 Postoperative factors

\begin{tabular}{llll}
\hline & $\begin{array}{l}\text { Underbody blanket } \\
(N=50)\end{array}$ & $\begin{array}{l}\text { Overbody blanket } \\
(N=49)\end{array}$ & $p$-value \\
\hline $\begin{array}{l}\text { Postoperative shivering } \\
\text { Yes }\end{array}$ & $1(2 \%)$ & $9(18.4 \%)$ & \\
$\quad$ Score 1 & $1(100 \%)$ & $2(22.2 \%)$ & \\
Score 2 & 0 & $6(66.7 \%)$ & \\
$\quad$ Score 3 & 0 & $1(11.1 \%)$ & 0.36 \\
No & $49(98 \%)$ & $40(81.6 \%)$ & \\
Surgical site infection & $4(8 \%)$ & $1(2 \%)$ & $0.04^{*}$ \\
Yes & $46(92 \%)$ & $48(98 \%)$ & $13(7-42)$ \\
No & $11(6-75)$ & & \\
Postoperative hospitalization (days) & &
\end{tabular}

Values are presented as medians (ranges) or number of patients (\%). Mann-Whitney- $U$ test was used for comparisons of ordinal data. Nominal data were compared using the Fisher's exact test

*Significant difference between groups 
the oxygen supply to the wounded tissues. This may have influenced the delay in wound healing. In a previous study, it was suggested that not only SSI, but also the initiation of solid food and the removal of sutures, affected the postoperative hospital length of stay [5]. In this study, we analyzed the relationship between intraoperative central temperature and SSI, although we did not collect any information on the relationship between SSI and initiation of solid food intake or removal of sutures. In future studies, we will aim to clarify the relation between intraoperative central temperature, suture removal, and initiation of solid food, and their effects in the postoperative hospital length of stay.

The results of this study showed that the use of an underbody blanket in surgery performed in the lithotomy position under general anesthesia led to an increase in central temperature compared with an overbody blanket. It also contributed to prevent postoperative shivering by decreasing the difference between central and peripheral temperature. We, therefore, recommend performing intraoperative temperature control using an underbody blanket in surgeries performed in the lithotomy position under general anesthesia.

\section{Limitations}

The results of this study may not be applicable to all surgeries performed with general anesthesia because this was a single-center, single-disease, randomized controlled trial. Moreover, intraoperative heating was stopped in 36\% of cases in the intervention group after consulting the anesthesiologist due to persistent hyperthermia. Hyperthermia at the time of awakening may lead to patient discomfort. In addition, it was decided that the timing to stop intraoperative heating should be decided after consultation with the anesthesiologist in charge, since the appropriate intraoperative central temperature has not been clearly determined. In the future, the range of intraoperative normothermic central temperature to be maintained even after the warm air heater is stopped should be determined.

In conclusion, the use of the underbody blanket had the following effects in comparison with the overbody blanket in the lithotomy position surgery under the general anesthesia. Adequate intraoperative central and peripheral temperature maintenance appears to have a preventing effect on postoperative shivering and to shorten the postoperative hospital length of stay.

Acknowledgements We gratefully acknowledge the work of past and present members of our medical center. We would like to thank Editage (www.editage.com) for English language editing.

Funding No financial support was used for this work.

\section{Compliance with ethical standards}

Disclosures Kentaro Hara, Hiromi Kuroda, Emi Matsuura, Yuji Ishimatsu, Sumihisa Honda, Hiroaki Takeshita, and Terumitsu Sawai, have no conflicts of interest or financial ties to disclose.

\section{References}

1. Morris RH, Wilkey BR (1970) The effects of ambient temperature on patient temperature during surgery not involving body cavities. Anesthesiology 32:102-107

2. Morris RH (1971) Influence of ambient temperature on patient temperature during intraabdominal surgery. Ann Surg 173:230-233

3. Morris RH (1971) Operating room temperature and the anesthetized, paralyzed patient. Arch Surg 102:95-97

4. Kurz A, Sessler DI, Lenhardt R (1996) Perioperative normothermia to reduce the incidence of surgical-wound infection and shorten hospitalization. N Engl J Med 334:1209-1215

5. Gustafsson UO, Scott MJ, Schwenk W, Demartines N, Roulin D, Francis N, McNaught CE, Macfie J, Liberman AS, Soop M, Hill A, Kennedy RH, Lobo DN, Fearon K, Ljungqvist O, Enhanced Recovery After Surgery (ERAS) Society, for Perioperative Care, European Society for Clinical Nutrition and Metabolism (ESPEN), International Association for Surgical Metabolism and Nutrition (IASMEN) (2013) Guidelines for perioperative care in elective colonic surgery: enhanced recovery after surgery (ERAS $®)$ Society recommendations. World J Surg 37:259-284

6. Mason SE, Kinross JM, Hendricks J, Arulampalam TH (2017) Postoperative hypothermia and surgical site infection following peritoneal insufflation with warm, humidified carbon dioxide during laparoscopic colorectal surgery: a cohort study with costeffectiveness analysis. Surg Endosc 31:1923-1929

7. Nieh HC, Su SF (2016) Meta-analysis: effectiveness of forced-air warming for prevention of perioperative hypothermia in surgical patients. J Adv Nurs 72:2294-2314

8. Ousey K, Edward KL, Lui S, Stephenson J, Walker K, Duff J, Leaper D (2017) Perioperative, local and systemic warming in surgical site infection: a systematic review and meta-analysis. J Wound Care 26:614-624

9. Su SF, Nieh HC (2018) Efficacy of forced-air warming for preventing perioperative hypothermia and related complications in patients undergoing laparoscopic surgery: a randomized controlled trial. Int J Nurs Pract 24:e12660

10. English MJ, Farmer C, Scott WA (1990) Heat loss in exposed volunteers. J Trauma 30:422-425

11. Bräuer A, Quintel M (2009) Forced-air warming: technology, physical background and practical aspects. Curr Opin Anesthesiol 22:769-774

12. Sessler DI (1997) Mild perioperative hypothermia. N Engl J Med 336:1730-1737

13. Luck AJ, Moyes D, Maddern GJ, Hewett PJ (1999) Core temperature changes during open and laparoscopic colorectal surgery. Surg Endosc 13:480-483

14. Insler SR, Bakri MH, Nageeb F, Mascha E, Mihaljevic T, Sessler DI (2008) An evaluation of a full-access underbody forced-air warming system during near-normothermic, on-pump cardiac surgery. Anesth Analg 106:746-750

15. Pu Y, Cen G, Sun J, Gong J, Zhang Y, Zhang M, Wu X, Zhang J, Qiu Z, Fang F (2014) Warming with an underbody warming system reduces intraoperative hypothermia in patients undergoing 
laparoscopic gastrointestinal surgery: a randomized controlled study. Int J Nurs Stud 51:181-189

16. Engelen S, Himpe D, Borms S, Berghmans J, Van Cauwelaert P, Dalton JE, Sessler DI (2011) An evaluation of underbody forcedair and resistive heating during hypothermic, on-pump cardiac surgery. Anaesthesia 66:104-110

17. Schulz KF, Altman DG, Moher D, CONSORT Group (2010) CONSORT 2010 statement: updated guidelines for reporting parallel group randomized trials. BMJ 340:c332

18. Lund CC (1944) The estimation of areas of burns. Surg Gynecol Obstet 79:352-358

19. Badjatia N, Strongilis E, Gordon E, Prescutti M, Fernandez L, Fernandez A, Buitrago M, Schmidt JM, Ostapkovich ND, Mayer SA (2008) Metabolic impact of shivering during therapeutic temperature modulation: the Bedside Shivering Assessment Scale. Stroke 39:3242-3247

20. Wagner VD (2010) Patient safety chiller: unplanned perioperative hypothermia. AORN J 92:567-571

21. Lynch S, Dixon J, Leary D (2010) Reducing the risk of unplanned perioperative hypothermia. AORN J 92:553-565

22. AORN Recommended Practices Committee (2007) Recommended practices for the prevention of unplanned perioperative hypothermia. AORN J 85:972-988

23. Torossian A, TEMMP (Thermoregulation in Europe Monitoring and Managing Patient Temperature) Study Group (2007) Survey on intraoperative temperature management in Europe. Eur J Anesthesiol 24:668-675

24. Forbes SS, Eskicioglu C, Nathens AB, Fenech DS, Laflamme C, McLean RF, McLeod RS, Best Practice in General Surgery Committee, University of Toronto (2009) Evidence-based guidelines for prevention of perioperative hypothermia. J Am Coll Surg 209:492-503

25. Michelson AD, MacGregor H, Barnard MR, Kestin AS, Rohrer MJ, Valeri CR (1994) Reversible inhibition of human platelet activation by hypothermia in vivo and in vitro. Thromb Haemost 71:633-640

26. Frank SM, Fleisher LA, Breslow MJ, Higgins MS, Olson KF, Kelly S, Beattie C (1997) Perioperative maintenance of normothermia reduces the incidence of morbid cardiac events: a randomized clinical trial. JAMA 277:1127-1134

27. Scott EM, Buckland R (2006) A systematic review of intraoperative warming to prevent postoperative complications. AORN J 83:1090-1113
28. Sheffield CW, Sessler DI, Hopf HW, Schroeder M, Moayeri A, Hunt TK, West JM (1996) Centrally and locally mediated thermoregulatory responses alter subcutaneous oxygen tension. Wound Repair Regen 4:339-345

29. Sessler DI (2008) Temperature monitoring and perioperative thermoregulation. Anesthesiology 109:318-338

30. Miyazaki R, Hoka S (2019) What is the predictor of the intraoperative body temperature in abdominal surgery? J Anesth 33:67-73

31. National Collaborating Centre for Nursing and Supportive Care (UK) (2008) The management of inadvertent perioperative hypothermia in adults. Royal College of Nursing (UK), London

32. Pauca AL, Savage RT, Simpson S, Roy RC (1984) Effect of pethidine, fentanyl, and morphine on postoperative shivering in man. Acta Anaesthesiol Scand 28:138-143

33. Sessler DI, Israel D, Pozos RS, Pozos M, Rubinstein EH (1988) Spontaneous postanesthetic tremor does not resemble thermoregulatory shivering. Anesthesiology 68:843-850

34. Pflug AE, Aasheim GM, Foster C, Martin RW (1978) Prevention of postanesthesia shivering. Can Anaesth Soc J 25:43-49

35. Sharkey A, Gulden RH, Lipton JM, Giesecke AH (1993) Effect of radiant heat on the metabolic cost of postoperative shivering. Br J Aneasth 70:449-450

36. Sessler DI, Rubinstein EH, Moayeri A (1991) Physiologic responses to mild perianesthetic hypothermia in humans. Anesthesiology 75:594-610

37. Sessler DI, McGuire J, Moayeri A, Hynson J (1991) Isofluraneinduced vasodilation minimally increases cutaneous heat loss. Anesthesiology 74:226-232

38. Hynson JM, Sessler DI, Moayeri A, McGuire J, Schroeder M (1993) The effects of preinduction warming on temperature and blood pressure during propofol/nitrous oxide anesthesia. Anesthesiology 79:219-228

39. Kuroki C, Godai K, Hasegawa-Moriyama M, Kuniyoshi T, Matsunaga A, Kanmura Y, Kuwaki T (2014) Perfusion index as a possible predictor for postanesthetic shivering. J Anesth 28:19-25

40. Cheng C, Matsukawa T, Sessler DI, Ozaki M, Kurz A, Merrifield B, Lin H, Olofsson P (1995) Increasing mean skin temperature linearly reduces the core-temperature thresholds for vasoconstriction and shivering in humans. Anesthesiology 82:1160-1168

Publisher's Note Springer Nature remains neutral with regard to jurisdictional claims in published maps and institutional affiliations. 